\title{
Correction to: The Relationship Between Training Load and Injury in Athletes: A Systematic Review
}

\author{
Timothy G. Eckard ${ }^{1}\left(\mathbb{D} \cdot\right.$ Darin A. Padua $^{1}$ (1) $\cdot$ Darren W. Hearn ${ }^{1} \cdot$ Brett S. Pexa ${ }^{1} \cdot$ Barnett S. Frank $^{1}$ (1)
}

Published online: 7 April 2020

C) Springer Nature Switzerland AG 2020

\section{Correction to: Sports Medicine (2018) 48:1929-1961 https://doi.org/10.1007/s40279-018-0951-z}

Page 1952, Table 1, row 1, column 4 ("Results"): The following sentence, which previously read:

"Cox proportional hazards regression models with frailty found no difference in injured vs. unin-jured players with week-to-week changes of $<20,20-60$, and $>60 \%$, controlling for scapular con-trol, isometric rotational and abduction strength, and shoulder range of motion ( $p$ value ranges 0.09-0.68)."

should read:

"Shoulder injury rate was nearly twice as high in the week following a $60 \%$ or greater increase in handball load when compared with a decrease or a small-to-moderate increase in handball load <20\% (HR 1.91;95\% CI 1.00-3.70, $\mathrm{p}=0.05$ ). Players with reduced external rotational strength had a greater shoulder injury rate than those with normal strength when increasing their weekly handball load between 20-60\% compared with players with a weekly increase or decrease below 20\% (HR 4.0; 95\% CI 1.1-15.2, $\mathrm{p}=0.04$ ). Likewise, those with scapular dyskinesis had a greater shoulder injury rate than those with normal control when progressing between 20-60\% compared with players with a weekly increase or decrease below $20 \%$ (HR 4.8; 95\% CI $1.3-18.3, \mathrm{p}=0.02) . "$

The original article can be found online at https://doi.org/10.1007/ s40279-018-0951-z.

Timothy G. Eckard

eckardtg@email.unc.edu

1 Department of Exercise and Sport Science, University of North Carolina at Chapel Hill, Fetzer Hall CB \#8700, Chapel Hill, NC 27599-8700, USA 